\title{
Comparison of the Accuracyand Time Efficiency of Two Different digital Impressions of Single Tooth Implant Treatments
}

\author{
Muhammed Alibrahim (D), Yilmaz Umut Aslan \\ Department of Prosthodontics, Faculty of Dentistry, Marmara University, Istanbul, Turkey
}

Correspondence Author: Yilmaz Umut Aslan

E-mail: umut.aslan@marmara.edu.tr

Received: $15.01 .2020 \quad$ Accepted: 17.02 .2020

\begin{abstract}
Objective: Over the last decades, techniques and materials have evolved with the improvement in digital technology. Computer-aided impressions have been transforming the dental implant field with these developments. The aim of this in vivo study was to compare the accuracy and time efficiency between two intraoral scanning systems in single tooth implant treatment.

Methods: 10 patients with single tooth bone level implant (Straumann, Basel, Switzerland) received one conventional impression with polyvinyl siloxane and three scans with 2 different intra-oral scanners (CEREC AC Omnicam and Straumann CARES IOS). The time required for the impressions was measured at this stage. The casts obtained from conventional impressions were scanned as the master model to evaluate accuracy. Digital impression files were analyzed using a software (Geomagic Control). Independent Samples Test was performed for trueness and precision. One-way ANOVA was executed for time efficiency. Least significant difference test for post hoc comparison was conducted $(p<0.05)$.
\end{abstract}

Results: The differences between the two systems regarding trueness and precision were not statistically significant $(P>0.05)$, but a statistically significant difference was found in the time efficiency $(P<0.05)$. CEREC AC showed the lowest mean values in time measures.

Conclusions: There was no difference regarding accuracy in comparison between CEREC AC Omnicam and CARES. CEREC AC Omnicam was found to be superior in terms of time efficiency in comparison to CARES and conventional impressions.

Keywords: Intraoral digital scanning, Implant impression, Accuracy, CAD/CAM

\section{INTRODUCTION}

Impressions have been used since the end of eighteenth century in the dental field, and still very essential in the practice of dentistry. Throughout the past two centuries, making dental impressions have greatly evolved, including compound, molded wax, synthetic rubbers and reversible and irreversible hydrocolloids. The 20th century showed outstanding advances in technology, and digital impressions came about in the 1980's for use in dentistry. In the decades following till recently, digital impression techniques have been evolving and their uses still broadening. Digital impressions and 3D models used widely in the application of dental field and dental specialties. Uses of digital models for prosthodontics contain analysis of occlusion, appliance design and production, treatment simulation and treatment effects (1).

The main reason digital impression technology has not been fully integrated into modern dentistry is the endurance of conventional impression techniques. These methods include hydrocolloid and elastomeric materials, such as alginate, polyether, and polyvinyl siloxane. The advantage of these materials is that they are well accepted, accurate and are generally inexpensive. However, these methods have been reported as unpleasant and not favored by the patients (2).

Additionally, these conventional impression techniques require stocking of raw materials and inventory as well as storage space for the stone casts. Digital impressions and the 3-dimensional models have huge advantages over plaster models and elastomeric materials, including more efficient storage and retrieval, superior durability, increased diagnostic versatility, decreased processing time and easier transferability (3).

The most familiar conventional impression materials in implant treatments are polyvinyl siloxane (PVS) and polyether (PE). These materials show great dimensional accuracy and have been successfully used in prosthodontics for years $(4,5)$. PVS is one of the commonly used impression materials 
in the field of dentistry; it is proved to guarantee accurate impression of the oral cavity (6-8).

The popularity of digital impression techniques has been increasing in dentistry fields due to the supported evidence of their accuracy (9). Since the advent of 3-dimensional scanning in dentistry, several dental and prosthodontics companies have started making digital scanners and comprehensive software analysis programs that supply many functions. These functions can ease procedures that were traditionally performed using physical models such as dental analysis, occlusal setups, and treatment predictions. The digital software innovates new procedures that were not presented with plaster casts, such as allowing visualization of tooth movements, the ability to overlay models and treatment outcomes (10).

There is a changing market of scanners available due to variety of intra-oral scanning systems. Digital scanners differ in acquisition techniques as well as in the unit's weight, speed and size. Digital scanners have different methods for the acquisition of intraoral impression, these methods are triangulation, parallel confocal, active wave front sampling, accordion fringe interferometry and three-dimensional inmotion video (11).

The 3D implant position can be captured digitally with an intra-oral optical scanner. One of the advantageous of intraoral optical scanner is that they can be used chairside for immediate digitization (12-14). Afterwards, the scanning data are saved as standard tessellation language (STL) files and can be used for digitalization and manufacturing of customized abutments and supra-structures with novel restorative materials (15).

Accuracy consists of trueness and precision (ISO 5725-1). Precision refers to how repeated scans match each other, thus the scanner with higher precision indicates a more repeatable and regular scan. Trueness indicates how different are the scanned measurement from the actual dimensions of the scanned structures (Fig 1). Therefore, the scanner with high trueness means that the scanner provides a matching or close result to the real dimensions of the scanned structure (16).

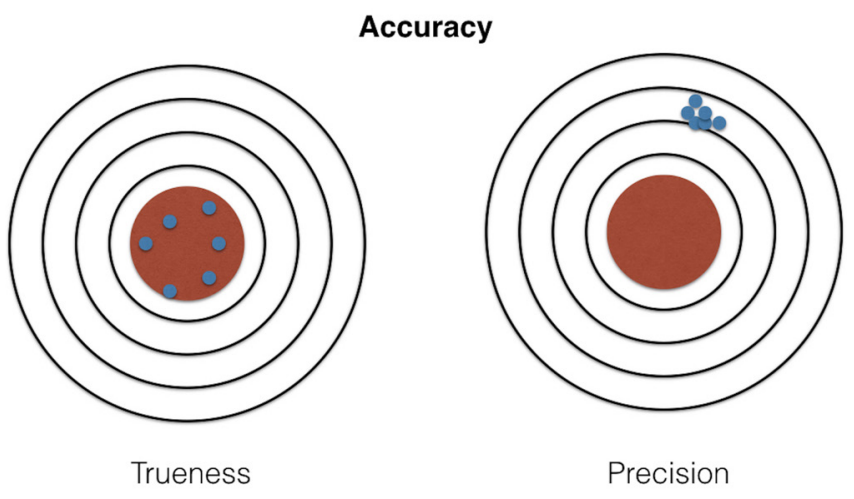

Figure 1. Truness and presicion
Accuracy is a prime aspect in function and aesthetics of indirect restorations. The fit of implant-supported dental restorations has been debated comprehensively in the literature. In contrast to natural teeth, osseointegrated implants cannot compensate for minor inaccuracies of the prostheses, as they are practically immobile. Their sensory discrimination is more limited than for teeth $(17,18)$.

The clinical time associated with chair-side digital scanning systems mostly plays significant role in the adaptation of this new technology. These days a few information concerning the learning curve and efficiency of the digital scanning techniques is presented and specific technologies in particular $(13,15)$.

The aim of this in vivo study is to compare the accuracy (trueness, precision) of a powder-free, continuous imaging impression system (CEREC AC Omnicam) and Multi-scan Imaging system with powder coating (Straumann CARES IOS) to determine the more accurate system and to compare the differences in time (impression time) required to create clinically acceptable impressions using material-based (polyvinyl siloxane [PVS]) monophasic impression with two chairside digital scanning systems (CEREC AC Omnicam and Straumann CARES IOS).

The null hypothesis was (1) because of requiring a layer of powder, the inhomogeneous powder thickness may affect the accuracy comparing with powder free system (2). There will be no difference in the time required to perform clinically acceptable impressions using material-based (polyvinyl siloxane [PVS]) monophasic method and chairside digital scanning techniques.

\section{METHODS}

This project was approved by the Ethics Committee of Marmara University in Istanbul, Turkey (Application No:201799). All of the volunteers recruited for the study accepted to sign the consent form.

Patients selected for the study were volunteers who applied to Marmara University with missing single posterior tooth and treated with a bone level implant (Straumann, Basel, Switzerland). Inclusion criteria were patients with good oral hygiene, no temporomandibular joint disease, aged at least eighteen years, intact hard and soft tissues around the implant area. Exclusion criteria were patients with advanced periodontitis affecting gingival recession.

Two intraoral scanning systems were evaluated in the study: CEREC AC Omnicam (Sirona Dental Systems, Sirona, Bensheim, Germany); Straumann CARES IOS (Straumann Cares Intraoral Scanner, Straumann, Basel, Switzerland). The study was conducted with 10 patients, each with osseintegrated single tooth bone level implant placed in posterior region and already had their healing caps were placed. After peri-implant hard and soft tissues were healed, every patient was received 1 conventional impression and 3 
repeated scans with each system of CEREC AC Omnicam and Straumann CARES IOS (Fig 2).

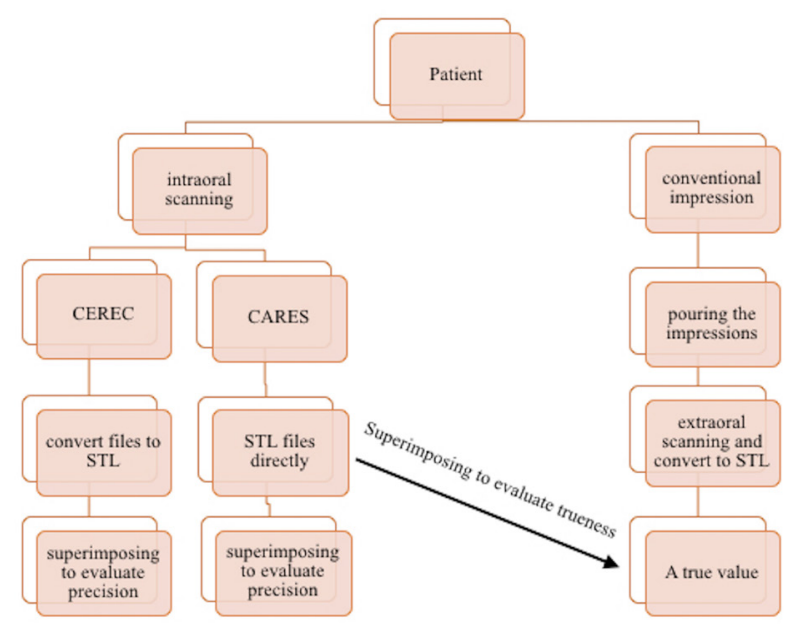

Figure 2. Workflow of the study

Manufacturer's guidelines were followed in the scan process. Saliva was removed, and vestibule mucosa were pulled by cheek and lip retractor. The camera of the scanner was aimed towards the scanned area. The camera tip was 5-10 millimeters away from the tooth or the scan body. The camera head was slid over the scanned area in a single direction gently to capture data. This process was then repeated two times, thus every patient had three digital impressions for each jaw for each system (Fig 3). To standardize the procedure, all scans were made by one dentist.

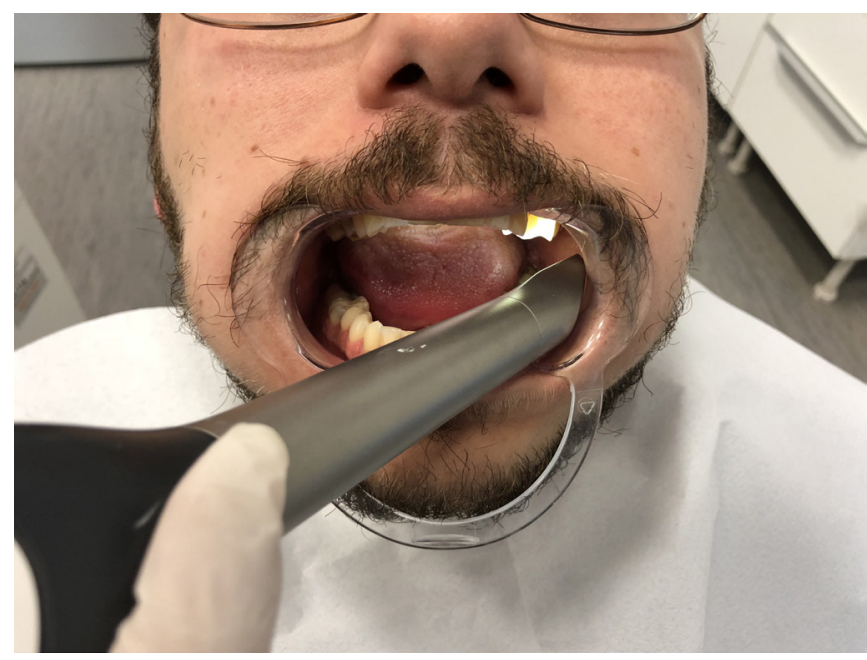

Figure 3. Digital scanning with CEREC AC Omnicam

A scan body (Straumann Bone Level RC) for Cares and (Sirona Dental Systems) for CEREC AC Omnicam was used to digitally transfer the implant position. During the conduction of digital scanning, some difficulties were countered while acquiring data in the interproximal margins, it was challenged to bring within the focal distance of the wand tip.

All the digital casts obtained with CEREC scanners were processed using CEREC SW 4.4.4 software to convert STL files. The STL file format was compatible with and able to be imported into most 3D model processing software.

Additionally, CARES scanner works in camera image impression and requires a powder coating on the scanned surfaces. Because of this, the teeth and the scan body in the quadrant were coated with a thin layer of titanium dioxide powder (Dentaco scan liquid, Essen - Germany) before scanning with CARES. In all cases, the opaque layer was renewed before each new scan (Fig 4).

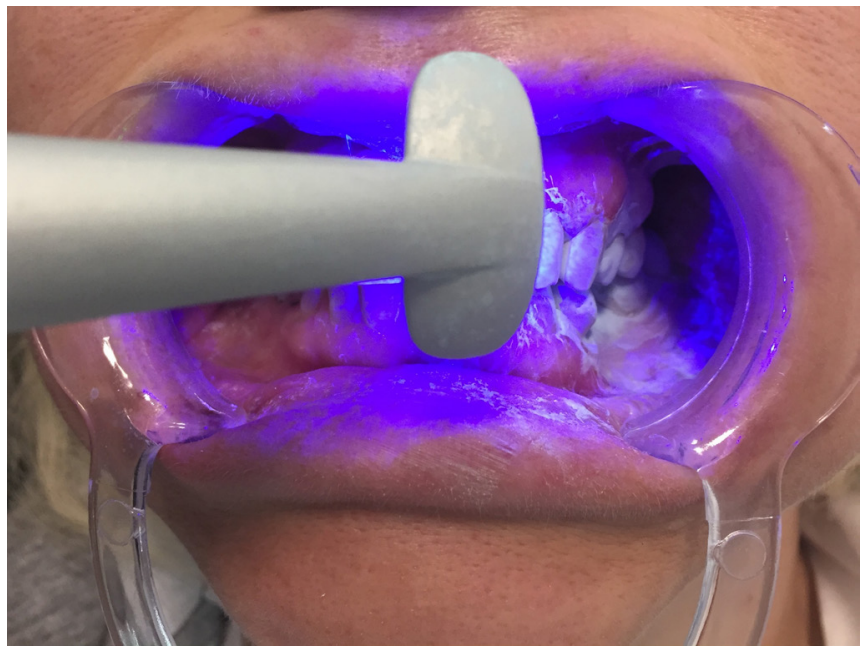

Figure 4. Digital scanning with Straumann CARES IOS (Powder was apllied)

Patients' conventional impressions were obtained right after the completion of intraoral digital scanning. Conventional impressions were made with PVS (Elite HD+, Zhermack SpA, Italy) using impression analog RC (Straumann Implant Level, Closed tray impression post - with guide screw and cap-, Straumann, Basel, Switzerland). Standard perforated metal stock trays (ASA Permalock; ASA Dental) were used to make PVS impressions. No tray adhesive was applied. Manufacturers' guidelines were followed in handling of the PVS materials.

The following acceptance criteria were used in of both impression methods: (1) accurate imprint of implants, (2) absence of voids on the surfaces, (3) proper reproduction of vestibule around peri-implant tissue. The impressions which did not meet the criteria were retaken for conventional impression or rescan for the digital impressions.

The time required for conventional and digital impressions was measured at this stage. Assessment of time efficiency was exercised after calculating the mean of required time results of every method.

Conventional impressions were disinfected for 10 minutes (Impresept; 3M ESPE, Seefeld, Germany) and suitable analog was seated over the impression post, afterwards 
the impression was poured with scannable Type IV dental stone (Vel-Mix ${ }^{\mathrm{TM}}$ Die Stone, California, USA). The impression trays were removed from the stone cast after 60 minutes according to manufacturers' guidelines, and the stone casts were stored at room temperature and humidity.

Each cast was digitized once by an optical lab scanner (3Shape D700 scanner, Copenhagen, Denmark) to obtain the STL file format and considered as reference models (Fig 5).

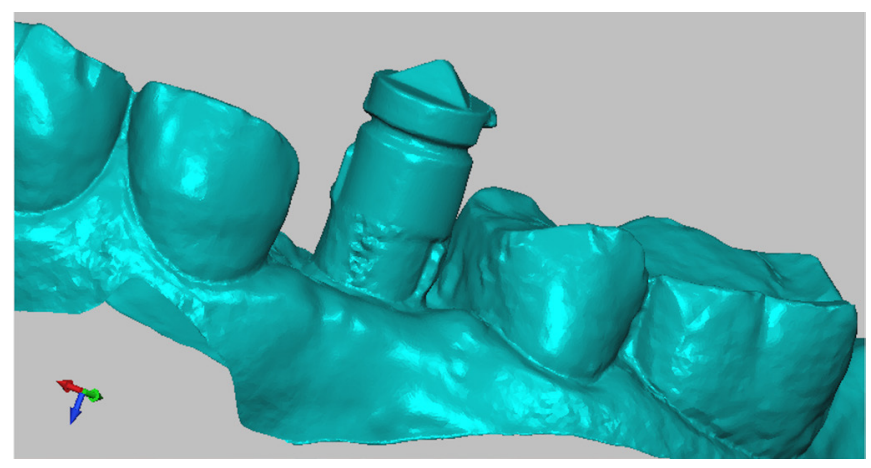

Figure 5. STL model of impression

All STL datasets were imported into the analyzing software (Geomagic Control; Geomagic, Morrisville, USA) and the STL data from each test group were pre-superimposed using CAD software (Geomagic Control; Geomagic, Morrisville, USA). To ensure an accurate superimposition, the models were trimmed to field of interest (the area of the implant, the adjacent teeth and about $1 \mathrm{~mm}$ of attached gingiva). Therefore, all irrelevant areas were eliminated manually to ensure precise superimposition and equal boundaries of all digital models (scan bodies were trimmed because of the difference in size between the systems). The trimmed models were imported into Geomagic Control again for overall compare.

For the 3D analysis, the digital models of the conventional group and 2 different intraoral scanned data group were superimposed by using the best-fit tool. Color maps to show the differences between two aligned models and deviation information were set to 20 color segments. The maximum and minimum critical values were set to $\pm 50 \mu \mathrm{m}$. With these settings, 3D analysis results were derived, and color maps were derived as qualitative results (Fig 6).

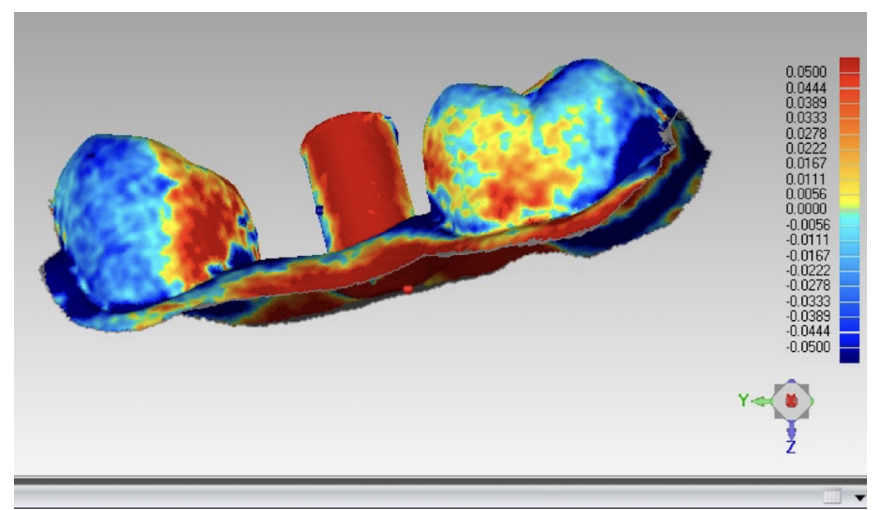

Figure 6. Superimposition of 3D models

\section{Accuracy analysis}

Trueness is defined as the deviation between digital impression (from each system) and a conventional impression (true value) of the same patient. Precision is defined as deviation between repeated digital scanning models obtained from the same patient with the same scanner. Following the $3 \mathrm{D}$ compare of every pairs, deviation information expressed as mean absolute deviation (average positive deviation + average negative deviation/ 2) accounting for trueness and standard deviation accounting for precision. The mean deviations for each patient were calculated.

\section{Time efficiency}

For execution time, all scanner systems were switched on and entered essential information of the case, performed the scan and processed the scan data. Next, it was allowed to a 2-minute intermission to cool down the scanner units before starting the next scanning.

The effective work time was calculated as the sum of the actual impression taking, we did not include the time needed for preparation of the IOS software, time spent powdering the dentition, entering appropriate scan modes, insertion of the scan-body, removal of the scan-body and positioning of the patient. Scan time for digital impressions began with activation of the scan wand.

As for the conventional impression-taking procedure we didn't include the time spent assembling the dispensing gun, applying adhesive to the tray if needed, Insertion and removal of the transfer post, disinfectant appliance and positioning the patient. Impression time for PVS impressions began with application of light body to the abutment tooth.

Time efficiency were independently recorded in minutes/ seconds $(\mathrm{m} / \mathrm{s})$ for both methods using a stopwatch. The number of required rescans and/ or impression retakes was documented and added for calculation if needed. No effect was identified for the randomized order of treatment starting with digital or conventional workflow.

For statistical analyses, one period was determined: intraoral time including scans of the scan body. For efficiency outcomes, the mean and standard deviation was calculated for each timed portion of the study. Measured time is recorded as min:sec and all data are presented as mean \pm SD. Comparison of mean working time including retakes/rescans.

\section{Statistical analysis}

Statistical analysis was performed with SPSS statistic software (version 21.0, SPSS Inc., Chicago, Illinois, United States). For each group classification, the mean value, the standard deviation (SD), the minimum and the maximum was calculated. For analyzing two dimensional deviations, Independent Samples Test was performed (for trueness and precision). And for analyzing three dimensional deviations, one-way ANOVA was executed (for time efficiency). LSD (least significant difference) test for post hoc comparison was conducted. The statistical significance was set at $(p<0.05)$. 


\section{RESULTS}

\section{Trueness}

After the models were imported to Geomagic Control software, the superimpositions were performed. In the terms of trueness of the digital systems, the lowest deviation respectively for the CEREC AC Omnicam and CARES group was $0.645 \mu \mathrm{m}$ and $0.549 \mu \mathrm{m}$. The highest deviation respectively for the CEREC AC and CARES group was $1.294 \mu \mathrm{m}$ and 1.188 $\mu \mathrm{m}$. The mean ( \pm standard) deviations were: $0.9627 \pm 0.1446$ $\mu \mathrm{m}$ for CEREC AC Omnicam and $0.9167 \pm 0.17264 \mu \mathrm{m}$ for CARES (Table 1).

The Independent Samples Test was performed after the descriptive analysis to determine whether there are any statistically significant differences among study groups. Independent Samples Test result is shown in table 4. According to Independent Samples Test, differences in trueness between CEREC AC Omnicam and CARES did not differ significantly $(P>0,05)$ (Table2).
Table 1. Descriptive statistics of trueness groups

\begin{tabular}{|c|c|c|c|c|c|c|c|}
\hline & \multirow{2}{*}{$N$} & \multirow{2}{*}{ Mean } & \multirow{2}{*}{$\begin{array}{c}\text { Std. } \\
\text { Deviation }\end{array}$} & \multirow{2}{*}{$\begin{array}{l}\text { Std. } \\
\text { Error }\end{array}$} & \multicolumn{2}{|c|}{$\begin{array}{l}\text { 95\% Confidence } \\
\text { Interval for Mean }\end{array}$} \\
\hline & & & & & & $\begin{array}{l}\text { Lower } \\
\text { Bound }\end{array}$ & $\begin{array}{l}\text { Upper } \\
\text { Bound }\end{array}$ \\
\hline \multirow{3}{*}{$\begin{array}{l}\text { average } \\
\text { positive } \\
\text { deviation }\end{array}$} & cerec & 10 & 0,992 & 0,132 & 0,044 & 0,891 & 1,093 \\
\hline & cares & 10 & 0,930 & 0,169 & 0,056 & 0,801 & 1,060 \\
\hline & Total & 20 & 0,961 & 0,150 & 0,035 & 0,886 & 1,036 \\
\hline \multirow{3}{*}{$\begin{array}{l}\text { average } \\
\text { negative } \\
\text { deviation }\end{array}$} & cerec & 10 & 0,934 & 0,190 & 0,063 & 0,788 & 1,079 \\
\hline & cares & 10 & 0,903 & 0,197 & 0,066 & 0,752 & 1,055 \\
\hline & Total & 20 & 0,918 & 0,189 & 0,044 & 0,825 & 1,012 \\
\hline \multirow{3}{*}{ c-d mean } & cerec & 10 & 0,963 & 0,145 & 0,048 & 0,852 & 1,074 \\
\hline & cares & 10 & 0,917 & 0,173 & 0,058 & 0,784 & 1,049 \\
\hline & Total & 20 & 0,940 & 0,156 & 0,037 & 0,862 & 1,018 \\
\hline
\end{tabular}

Table 2. Independent Samples Test result to determine trueness

\begin{tabular}{|c|c|c|c|c|c|c|c|c|c|c|}
\hline \multicolumn{11}{|c|}{ Independent Samples Test } \\
\hline & & \multicolumn{2}{|c|}{$\begin{array}{l}\text { Levene's Test for } \\
\text { Equality of Variances }\end{array}$} & \multicolumn{7}{|c|}{ t-test for Equality of Means } \\
\hline & & \multirow[t]{2}{*}{$F$} & \multirow[t]{2}{*}{ Sig. } & \multirow[t]{2}{*}{$\mathrm{t}$} & \multirow[t]{2}{*}{ df } & \multirow{2}{*}{$\begin{array}{c}\text { Sig } \\
\text { (2-tailed) }\end{array}$} & \multirow{2}{*}{$\begin{array}{c}\text { Mean } \\
\text { Difference }\end{array}$} & \multirow{2}{*}{$\begin{array}{l}\text { Std.Error } \\
\text { Difference }\end{array}$} & \multicolumn{2}{|c|}{$\begin{array}{l}\text { 95\% Confidence Interval } \\
\text { of the Difference }\end{array}$} \\
\hline & & & & & & & & & Lower & Upper \\
\hline \multirow{2}{*}{$\begin{array}{c}\text { average positive } \\
\text { deviation }\end{array}$} & $\begin{array}{l}\text { Equal variances } \\
\text { assumed }\end{array}$ & 0,699 & 0,415 & 0,864 & 16 & $0,400 *$ & 0,062 & 0,071 & $-0,090$ & 0,213 \\
\hline & $\begin{array}{l}\text { Equal variances } \\
\text { not assumed }\end{array}$ & & & 0,864 & 15,095 & 0,401 & 0,062 & 0,071 & $-0,090$ & 0,214 \\
\hline \multirow{2}{*}{$\begin{array}{l}\text { average negative } \\
\text { deviation }\end{array}$} & $\begin{array}{l}\text { Equal variances } \\
\text { assumed }\end{array}$ & 0,112 & 0,742 & 0,332 & 16 & $0,744^{*}$ & 0,030 & 0,091 & $-0,163$ & 0,224 \\
\hline & $\begin{array}{c}\text { Equal variances } \\
\text { not assumed }\end{array}$ & & & 0,332 & 15,976 & 0,744 & 0,030 & 0,091 & $-0,163$ & 0,224 \\
\hline \multirow{2}{*}{$c-d$ mean } & $\begin{array}{l}\text { Equal variances } \\
\text { assumed }\end{array}$ & 0,38 & 0,546 & 0,613 & 16 & $0,549 *$ & 0,046 & 0,075 & $-0,113$ & 0,205 \\
\hline & $\begin{array}{c}\text { Equal variances } \\
\text { not assumed }\end{array}$ & & & 0,613 & 15,524 & 0,549 & 0,046 & 0,075 & $-0,114$ & 0,206 \\
\hline
\end{tabular}

*. The mean difference is significant at the 0.05 level.

\section{Precision}

After the models were imported to Geomagic Control software, the superimpositions were done. In the terms of precision of the digital systems, the lowest deviation respectively for the CEREC AC and CARES group was 0.054 $\mu \mathrm{m}$ and $0.048 \mu \mathrm{m}$. The highest deviation respectively for the CEREC AC and CARES group was $0.235 \mu \mathrm{m}$ and $0.215 \mu \mathrm{m}$. Table 7 gives the mean values and their standard deviation for each parameter after superimposition. The measurement results (mean \pm standard deviation) for precision were: $0.1222 \pm 0.0479 \mu \mathrm{m}$ for CEREC AC Omnicam, 0.1040 \pm 0.0417 $\mu \mathrm{m}$ for CARES (Table 3).
The Independent Samples Test was performed after the descriptive analysis to determine whether there are any statistically significant differences among study groups. Independent Samples Test result is shown in table 4. According to Independent Samples Test, differences in precision between CEREC AC Omnicam and CARES was not significantly important ( $P>0.05)$.

On the basis of the results of this in vivo study, there was no difference regarding accuracy (trueness and precision) in comparison between CEREC AC Omnicam and CARES for the impression of single tooth implant. 
Table 3. Descriptive statistics of precision groups

\begin{tabular}{|c|c|c|c|c|c|c|c|}
\hline & & \multirow{2}{*}{$\mathrm{N}$} & \multirow{2}{*}{ Mean } & \multirow{2}{*}{ Std. Deviation } & \multirow{2}{*}{ Std. Error } & \multicolumn{2}{|c|}{ 95\%Confidence Interval for Mean } \\
\hline & & & & & & Lower Bound & Upper Bound \\
\hline \multirow{3}{*}{$\begin{array}{c}\text { superimposition } \\
1-2\end{array}$} & cerec & 10 & 0,112620 & 0,0467570 & 0,0147859 & 0,079172 & 0,146068 \\
\hline & cares & 10 & 0,096670 & 0,0299303 & 0,0094648 & 0,075259 & 0,118081 \\
\hline & Total & 20 & 0,104645 & 0,0390750 & 0,0087374 & 0,086357 & 0,122933 \\
\hline \multirow{3}{*}{$\begin{array}{c}\text { superimposition } \\
1-3\end{array}$} & cerec & 10 & 0,131890 & 0,0669412 & 0,0211687 & 0,084003 & 0,179777 \\
\hline & cares & 10 & 0,111470 & 0,0461100 & 0,0145813 & 0,078485 & 0,144455 \\
\hline & Total & 20 & 0,121680 & 0,0569165 & 0,0127269 & 0,095042 & 0,148318 \\
\hline \multirow{3}{*}{ c-d mean } & cerec & 10 & 0,122255 & 0,0479711 & 0,0151698 & 0,087939 & 0,156571 \\
\hline & cares & 10 & 0,104070 & 0,0346684 & 0,0109631 & 0,079270 & 0,128870 \\
\hline & Total & 20 & 0,113163 & 0,0417899 & 0,0093445 & 0,093604 & 0,132721 \\
\hline
\end{tabular}

Table 4. Independent Samples Test result to determine precision

\begin{tabular}{|c|c|c|c|c|c|c|c|c|c|c|}
\hline & & \multicolumn{2}{|c|}{$\begin{array}{c}\text { Levene's Test for } \\
\text { Equality of Variances }\end{array}$} & \multicolumn{7}{|c|}{ t-test for Equality of Means } \\
\hline & & \multirow[t]{2}{*}{$\mathrm{F}$} & \multirow[t]{2}{*}{ Sig. } & \multirow[t]{2}{*}{$\mathrm{t}$} & \multirow[t]{2}{*}{ df } & \multirow{2}{*}{$\begin{array}{c}\text { Sig. } \\
\text { (2-tailed) }\end{array}$} & \multirow{2}{*}{$\begin{array}{c}\text { Mean } \\
\text { Difference }\end{array}$} & \multirow{2}{*}{$\begin{array}{l}\text { Std. Error } \\
\text { Difference }\end{array}$} & \multicolumn{2}{|c|}{$\begin{array}{l}\text { 95\% Confidence Interval of } \\
\text { the Difference }\end{array}$} \\
\hline & & & & & & & & & Lower & Upper \\
\hline \multirow{2}{*}{$\begin{array}{c}\text { superimposition } \\
1-2\end{array}$} & $\begin{array}{c}\text { Equal } \\
\text { variances } \\
\text { assumed }\end{array}$ & 1,516 & 0,234 & 0,909 & 18 & $0,376 *$ & 0,0159500 & 0,0175557 & $-0,0209332$ & 0,0528332 \\
\hline & $\begin{array}{c}\text { Equal } \\
\text { variances not } \\
\text { assumed }\end{array}$ & & & 0,909 & 15,315 & 0,378 & 0,0159500 & 0,0175557 & $-0,0214022$ & 0,0533022 \\
\hline \multirow{2}{*}{$\begin{array}{c}\text { superimposition } \\
1-3\end{array}$} & $\begin{array}{c}\text { Equal } \\
\text { variances } \\
\text { assumed }\end{array}$ & 3,530 & 0,077 & 0,794 & 18 & $0,437 *$ & 0,0204200 & 0,0257046 & $-0,0335833$ & 0,0744233 \\
\hline & $\begin{array}{c}\text { Equal } \\
\text { variances not } \\
\text { assumed }\end{array}$ & & & 0,794 & 15,971 & 0,439 & 0,0204200 & 0,0257046 & $-0,0340793$ & 0,0749193 \\
\hline \multirow{2}{*}{$c-d$ mean } & $\begin{array}{c}\text { Equal } \\
\text { variances } \\
\text { assumed }\end{array}$ & 1,190 & 0,290 & 0,972 & 18 & $0,344 *$ & 0,0181850 & 0,0187166 & $-0,0211372$ & 0,0575072 \\
\hline & $\begin{array}{c}\text { Equal } \\
\text { variances not } \\
\text { assumed }\end{array}$ & & & 0,972 & 16,386 & 0,345 & 0,0181850 & 0,0187166 & $-0,0214166$ & 0,0577866 \\
\hline
\end{tabular}

*. The mean difference is significant at the 0.05 level.

\section{Time efficiency}

The efficiency of impression techniques was evaluated by measuring working time in minutes/seconds $(\mathrm{m} / \mathrm{s})$ and numerical variables of interest were descriptively analyzed with sample means and standard deviations (SD). The best result was seen respectively in group CEREC AC Omnicam with $3.02 \mathrm{~min}$, conventional $4.55 \mathrm{~min}$ and CARES $5.00 \mathrm{~min}$.
The longest time was seen respectively in group conventional $6.60 \mathrm{~min}$, CARES $6.45 \mathrm{~min}$ and CEREC $4.54 \mathrm{~min}$.

Table 5 gives the mean values and their standard deviation, as well as the minimum, median, maximum and $95 \%$ confidence interval for each parameter. The measurement results (mean \pm standard deviation) for time efficiency were: $3.619 \pm 0.4597 \mathrm{~m} / \mathrm{s}$ for CEREC AC Omnicam, 5.368 $\pm 0.2590 \mathrm{~m} / \mathrm{s}$ for CARES, $5.402 \pm 0.7068 \mathrm{~m} / \mathrm{s}$ for conventional.

Table 5. Descriptive statistics of time efficiency groups

\begin{tabular}{|c|c|c|c|c|c|c|}
\hline & Number & Mean & Std. Deviation & Std. Error & \multicolumn{2}{|c|}{ 95\% Confidence Interval for Mean } \\
\cline { 3 - 6 } & 10 & 3,6190 & 0,45975 & 0,14538 & 3,2901 \\
\hline cerec & 10 & 5,3680 & 0,25909 & 0,08193 & 5,1827 \\
\hline cares & 10 & 5,4020 & 0,70684 & 0,22352 & 4,8964 \\
\hline Total & 30 & 4,7963 & 0,97910 & 0,17876 & 5,4307 \\
\hline
\end{tabular}


The one-way analysis of variance (ANOVA) test was performed after the descriptive analysis to determine whether there are any statistically significant differences among study groups. ANOVA test result is shown in Table 6. According to ANOVA, variations in time efficiency between CEREC AC Omnicam, CARES and conventional techniques differ significantly $(P<0.05)$.

Table 6. ANOVA test results to determine time efficiency

\begin{tabular}{|c|c|c|c|c|c|}
\hline & Sum of Squares & df & Mean Square & F & Sig. \\
\hline Between Groups & 20,797 & 2 & 10,399 & 40,092 & .000 \\
\hline Within Groups & 7,003 & 27 &, 259 & & \\
\hline Total & 27,800 & 29 & & & \\
\hline
\end{tabular}

To determine differences among the study groups LSD (least significant difference) test for post hoc comparison was performed. To detect the different group least significant difference LSD test was done, LSD results are detailed in Table 7. The LSD test results showed significant difference among the study groups according to statistical significance $(p<0.05)$, and accordingly it indicates that CEREC AC Omnicam group $(3.619 \pm 0.4597 \mathrm{~m} / \mathrm{s})$ was significantly more time efficient than CARES group $(5.368 \pm 0.2590 \mathrm{~m} / \mathrm{s})$ and conventional group $(5.402 \pm 0.7068 \mathrm{~m} / \mathrm{s})$. There were no significant differences between CARES and conventional impressions in the same manner.

According to the results of the present in vivo study, CEREC AC Omnicam was found to be superior regarding time efficiency in comparison with CARES and conventional approaches and might accelerate the work flow of making impressions.

Table 7. LSD test results on study groups

\begin{tabular}{|c|c|c|c|c|c|c|}
\hline \multicolumn{7}{|c|}{ Multiple Comparisons } \\
\hline \multirow{2}{*}{ (I) group } & \multirow{2}{*}{ (J) group } & \multirow{2}{*}{ Mean Difference (I-J) } & \multirow{2}{*}{ Std. Error } & \multirow{2}{*}{ Sig. } & \multicolumn{2}{|c|}{$95 \%$ Confidence Interval } \\
\hline & & & & & Lower Bound & Upper Bounc \\
\hline \multirow{2}{*}{ cerec } & cares & $-1,74900^{*}$ & ,22776 & .000 & $-2,3137$ & $-1,1843$ \\
\hline & conventional & $-1,78300^{*}$ & ,22776 & .000 & $-2,3477$ & $-1,2183$ \\
\hline \multirow{2}{*}{ cares } & cerec & $1,74900^{*}$ & ,22776 & .000 & 1,1843 & 2,3137 \\
\hline & conventional &,- 03400 & ,22776 & ,988 &,- 5987 &, 5307 \\
\hline \multirow{2}{*}{ conventional } & cerec & $1,78300^{*}$ & ,22776 & 000 & 1,2183 & 2,3477 \\
\hline & cares &, 03400 & ,22776 & ,988 &,- 5307 & ,5987 \\
\hline
\end{tabular}

*. The mean difference is significant at the 0.05 level.

\section{DISCUSSION}

The null hypothesis was (1) due to the requirement of layer of powder, the inhomogeneous powder thickness may affect the accuracy comparing with powder free system (2). There will be no difference in the time required to perform clinically acceptable impressions using material-based (polyvinyl siloxane) and chairside digital scanning techniques.

According to results of the present study, the null hypothesis (1) was rejected, no significant differences were found between the two scanning systems regarding both trueness and precision (2). The $2^{\text {nd }}$ null hypothesis was rejected, a significant deference $(p<0,05)$ were found in the time efficiency, CEREC AC Omnicam showed the lowest mean deviation and consequently more time efficient than CARES and conventional impressions. No significant differences were found between CARES and the conventional method regarding the time efficiency.

In the present study PVS impression material was used as golden standard to obtain STL files of conventional impressions $(6,7)$. The deficiencies reported with elastomeric impression materials were technique sensitivity, patient discomfort, dimensional changes, dental stone and disinfection agent's distortion (19).

There are several studies related to patient outcomes for digital implant impressions with those for conventional implant impressions (10). These clinical studies showed consistent findings with an overall patients' preference significantly in favor of the intraoral optical scanner, rather than the conventional method regarding the capturing of the three-dimensional implant position. Moreover, one pilot study assessed the operators' perceptions when comparing conventional and digital impressions in a standardized setting for single-implant crowns (20). Study participants were performing both methods on a phantom model. In this study, the digital systems were higher acceptance than the conventional impressions as the other studies $(10,21)$.

Accuracy of digital impressions can also be affected by scanbody related factors (22). Characteristics of the scan bodies could be another source of errors. Shorter and less visible scan bodies can negatively influence the accuracy. It was recommended that longer scan bodies should be used with deep-placed implants. One of the studies included in the systematic review used longer scan bodies, which could also contribute to better measured accuracy. Sharp angles of the scan bodies could negatively influence scan accuracy (5). To ensure the standardization, same scan-bodies recommended by the systems were used in the present study.

Spraying of the scan bodies with powder is still needed for some of the intra-oral scanners to reduce the reflections and 
aid the stitching of the images. Clinically, a slight powder layer might be also used as an indicator for moisture, and powdering could potentially influence the accuracy of scanning through homogeneity and thickness of spray. It was reported that experienced clinicians achieved greater homogeneity and thinner coatings. Therefore, it is recommended to use only light dusting on the surfaces to be scanned (23). In the present study, the powdering did not affect the results of the accuracy.

There are few clinical studies concerning digital implant impressions that are currently available. Partially quadrantlike intraoral optical scans and CAD/CAM technology revealed a reduced treatment method (4). Additionally, the need for chairside modifications, such as secondary grinding and polishing, can be decreased, or may not even be required, within a complete digitized procedure using monolithic restorations. This increases the time efficiency and may also minimize the threat of cracks and chipping as an outcome of the absence of veneered ceramics (12). In this study, the measurement results (mean \pm standard deviation) for trueness were: $0.9627 \pm 0.1446 \mu \mathrm{m}$ for CEREC AC Omnicam, $0.91678 \pm 0.17264 \mu \mathrm{m}$ for CARES, while the measurement results (mean \pm standard deviation) for precision were: $0.1222 \pm 0.0479 \mu \mathrm{m}$ for CEREC AC Omnicam, 0.1040 \pm 0.0417 $\mu \mathrm{m}$ for CARES. In the terms of accuracy (trueness and precision) there was no significant differences between two systems.

Lee and Gallucci (20) assessed the efficiency of digital and conventional impressions of single-implant reconstructions models. The mean fully treatment time was $24.42 \mathrm{~min}$ for the conventional method and $12.29 \mathrm{~min}$ for the digital method. The researchers incorporated the preparation time and procedure durations for retakes or rescans in their calculation. According to this in vivo study, one sextant was scanned from each patient to examine the difference in time efficiency (impression taking time only) between the digital and conventional techniques. In another study, the time in making impression of 50 single implants were recorded as $12.13 \mathrm{~min}$ for conventional (open tray, polyether), while CEREC AC Omnicam required only 6.39 min although complete arch scanning was performed. ${ }^{24}$ In the present study, the results (mean \pm standard deviation) for time efficiency were: $3.619 \pm 0.4597 \mathrm{~m} / \mathrm{s}$ for CEREC AC Omnicam, 5.368 \pm 0.2590 $\mathrm{m} / \mathrm{s}$ for CARES, $5.402 \pm 0.7068 \mathrm{~m} / \mathrm{s}$ for conventional, thus the CEREC AC Omnicam were more time efficient than the CARES and conventional approaches.

In comparing the chairside time required to complete each type of impression, the CARES digital impression required significantly more time than the other two impression groups. The CEREC AC Omnicam impressions had the shortest median time. It should be noted that these measurements include only the time spent making the impression, and do not take into consideration the time required to disinfect and process any of the impressions.

The limitations of the present study were the scanning a single implant. There are more studies needed to evaluate multiple implants and wider scanning surface in the terms of time efficiency.

\section{CONCLUSION}

Within the limitation of this in vivo study, both of the intraoral scanning systems were capable to give sextant impression of single tooth implant with clinically satisfying accuracy (trueness and precision), there were differences between the digital and conventional methods regarding impression taking time, CEREC AC Omnicam was more time efficient than CARES and the conventional way.

\section{REFERENCES}

[1] Kusnoto B, Evans C. Reliability of a 3D surface laser scanner for orthodontic applications. Am J Orthod Dentofacial Orthop 2002; 122:342-348.

[2] Hacker T, Heydecke G, Reissmann DR. Impact of procedures during prosthodontic treatment on patients' perceived burdens. Journal of Dentistry 2015; 43:51-57.

[3] Joffe L. Current Products and Practices OrthoCAD ${ }^{\mathrm{Tm}}$ : digital models for a digital era. J Orthod 2014; 3:344-347.

[4] Christensen GJ. Will digital impressions eliminate the current problems with conventional impressions? J Am Dent Assoc 2008; 139:761-763.

[5] Chochlidakis MK, Papaspyridakos P, Geminiani A, Chen CJ, Feng J, Ercoli C. Digital versus conventional impressions for fixed prosthodontics: A systematic review and meta-analysis. J Prosthet Dent 2016; 116:184-190

[6] Sorrentino R, Gherlone EF, Calesini G, Zarone F. Effect of implant angulation, connection length, and impression material on the dimensional accuracy of implant impressions: An in vitro comparative study. Clin Implant Dent Relat Res 2010; 12:63-76.

[7] Aslan YU, Ozkan Y. Comparing volumetric dimensional stability and accuracy of newly formulated polyvinyl siloxanether, polyvinyl siloxane and polyether impression materials using micro-computed tomography. Clin Exp Health Sci. 2019; 9:94100.

[8] Vecsei B, Joós-Kovács G, Borbely J, Hermann P. Comparison of the accuracy of direct and indirect three-dimensional digitizing processes for CAD/CAM systems - An in vitro study. J Prosthodont Res. 2016; 61:177-184.

[9] Kravitz N, Groth C, Jones P, Graham J, Redmond WR. Intraoral Digital Scanners. J Clin Orthod 2014; 48:337-347.

[10] Wismeijer D, Mans R, van Genuchten M, Reijers HA. Patients' preferences when comparing analogue implant impressions using a polyether impression material versus digital impressions (Intraoral Scan) of dental implants. Clin Oral Implants Res 2014; 25:1113-1118.

[11] Ahlholm P, Sipilä K, Vallittu P, Jakonen M, Kotiranta U. Digital versus conventional impressions in fixed prosthodontics: a review. J Prosthodont 2016; 27:35-41

[12] Christensen GJ. Impressions are changing: deciding on conventional, digital or digital plus in-office milling. J Am Dent Assoc 2009; 140:1301-1304.

[13] Joda T, Bragger U. Digital vs. conventional implant prosthetic workflows: a cost/time analysis. Clin Oral Implants Res 2015; 26:1430-1435. 
[14] Fasbinder DJ. Computerized technology for restorative dentistry. Am J Dent 2013; 26:115-120.

[15] Joda T, Bragger U. Time-efficiency analysis of the treatment with monolithic implant crowns in a digital workflow: a randomized controlled trial. Clin Oral Implants Res 2016; 27;1401-1406.

[16] Patzelt SB, Emmanouilidi A, Stampf S, Strub JR, Att W. Accuracy of full-arch scans using intraoral scanners. Clin Oral Invisting 2014; 18:1687-1694.

[17] Boldt J, Knapp W, Proff P, Rottner K, Richter EJ. Measurement of tooth and implant mobility under physiological loading conditions. Ann Anat 2012; 194:185-189.

[18] Gimenez BD, Ozcan MD, Martinez-Rus FD, Pradies GD. Accuracy of a digital impression system based on active wavefront sampling technology for implants considering operator experience, implant angulation, and depth. Clin Implant Dent Relat Res 2015; 17:54-64.

[19] Correia AR, Sampaio Fernandes JC, Cardoso JA, et al. CADCAM: informatics applied to fixed prosthodontics. Rev Odontol UNESP 2006; 35:183-189.
[20] Lee SJ, Gallucci GO. Digital vs. conventional implant impressions: efficiency outcomes. Clin Oral Implants Res 2013; 24:111-115.

[21] Yuzbasioglu E, Kurt H, Turunc R, Bilir H. Comparison of digital and conventional impression techniques: evaluation of patients' perception, treatment comfort, effectiveness and clinical outcomes. BMC Oral Health 2014; 30;14:10. doi: 10.1186/1472-6831-14-10

[22] Mangano, F., Gandolfi, A., Luongo, G. et al. Intraoral scanners in dentistry: a review of the current literature. BMC Oral Health 17, 149 (2017). doi.org/10.1186/s12903.017.0442-x

[23] Carvalho TF, Lima JFM, De Matos JDM, Lopes GRS, De Vasconcelos JEL, Zogheib LV, De Castro DSM. Evaluation of the accuracy of conventional and digital methods of obtaining dental Impressions. Int J Odontostomat 2018; 12:368-375.

[24] Schepke U, Meijer HJA, Kerdijk W, Cune MS. Digital versus analog complete-arch impressions for single-unit premolar implant crowns: Operating time and patient preference. J Prosthet Dent 2015; 114:403-406. 